\title{
Altered mucosa-associated microbiota in the ileum and colon of neonatal calves in response to delayed first colostrum feeding
}

\author{
T. Ma, ${ }^{1,2}$ E. O’Hara, ${ }^{2}$ Y. Song, ${ }^{2}$ A. J. Fischer, ${ }^{2}$ Z. He, ${ }^{2}$ M. A. Steele,,${ }^{2,3 *}$ and L. L. Guan ${ }^{2 *}$ \\ ${ }^{1}$ Feed Research Institute, Chinese Academy of Agricultural Sciences, Key Laboratory of Feed Biotechnology of the Ministry of Agriculture, \\ Beijing 100081, China \\ ${ }^{2}$ Department of Agricultural, Food and Nutritional Science, University of Alberta, Edmonton, Canada AB T6G 2P5 \\ ${ }^{3}$ Department of Animal Biosciences, University of Guelph, Ontario, Canada N1G 2W1
}

\section{ABSTRACT}

The present study investigated whether delaying the first feeding of colostrum affected ileum and colon mucosa-associated microbiota in calves. Twenty-seven male Holstein calves were randomly assigned to 1 of 3 groups, fed colostrum at $45 \mathrm{~min}, 6 \mathrm{~h}$, and $12 \mathrm{~h}$ after birth, respectively. Ileum and colon mucosa were collected at $51 \mathrm{~h}$ after birth, and their associated microbial profiles were assessed using amplicon sequencing. Both ileum and colon mucosa-associated microbiota were predominated by genus Escherichia-Shigella. The negative correlation between the molar proportion of shortchain fatty acids (SCFA) and ileum mucosa-associated opportunistic pathogens, and the positive correlation between the molar proportion of SCFA and colon mucosa-associated beneficial bacteria, suggest that SCFA might play an important role in maintaining the gut health of 2-d-old calves. A higher relative abundance of ileum mucosa-associated Enterococcus and Streptococcus was detected when the first colostrum feeding was delayed for $12 \mathrm{~h}$. The relative abundance of colon mucosa-associated Lactobacillus tended to be lower in calves fed colostrum $12 \mathrm{~h}$ than those under the other 2 treatments, whereas that of Faecalibacterium tended to be lower in calves fed colostrum immediately after birth than those fed colostrum 6 and $12 \mathrm{~h}$ after birth, respectively. Our findings suggest that delayed first colostrum feeding affects the establishment of ileum and colon mucosa-associated bacteria, which may have long-term effects on gut health of calves.

Key words: colostrum, newborn dairy calf, gut, mucosa-associated microbiota

Received December 9, 2018.

Accepted April 23, 2019.

*Corresponding authors: lguan@ualberta.ca, masteele@uoguelph.ca

\section{INTRODUCTION}

Neonatal ruminants are characterized as "pseudomonogastric" before their transition to functionally developed rumen digestion after weaning (Baldwin et al., 2004). Their intestinal tract not only serves as the main site of liquid feed digestion and nutrient absorption but also plays a pivotal role in mucosal immune functions (Ruth and Field, 2013). A well-developed intestinal mucosal immune system can tolerate commensal microbes as well as recognize pathogenic microbes in order to protect the host from infection (Tourneur and Chassin, 2013). Studies have revealed that changes in initial colonization of gut microbiota and the resulting immune functional development have long-lasting effects on mitigating gastrointestinal and metabolic diseases in humans (Kalliomäki et al., 2008; Rautava et al., 2012). Dynamic fluctuations or dysbiosis of gut microbiota in neonates who undergo rapid changes, including diet, environment, or physiological status, could break the balance between host and microbes. Therefore, establishment and maintenance of positive interactions between the host and intestinal microbiota are key to maintaining the health of neonates (Sommer and Bäckhed, 2013). However, few attempts have been made to understand how external factors, especially early-life nutrition or feeding regimen, affect intestinal colonization of microbiota in neonatal ruminants.

Colostrum is the first source of nutrition after birth, and it contains a mixture of immunoglobulins that play fundamental roles in passive transfer of immunity to newborn calves. These immunoglobulins protect the hypo-agammaglobulinemic neonatal calf against pathogens and other environmental challenges that they may face after birth (Bendixen et al., 2011). Failure to adequately absorb colostral immunoglobulins within the first hours of life results in failure of passive transfer of immunity, leading to high mortality rates ranging from 8 to $25 \%$ in calves (Raboisson et al., 2016). Although the timing of first colostrum feeding is critical in terms 
of successful passive transfer of immunity, delay in feeding colostrum often happens on farms when calves are born at night. To date, previous studies have mainly focused on the effects of delayed colostrum feeding on plasma parameters in calves (Hammon et al., 2000) and lambs (Hernández-Castellano et al., 2014), to evaluate transfer efficiency of immunoglobulins from colostrum to calf. Only a few studies have evaluated the effect of colostrum feeding strategy on intestinal microbial colonization in newborn calves. A recent study showed that feeding colostrum within an hour after birth significantly increased the proportion of Bifidobacterium attached to the small intestine mucosa of calves at 12 $\mathrm{h}$ after birth, compared with those not fed colostrum (Malmuthuge et al., 2015). More recently, Fischer et al. (2018) reported that at $2 \mathrm{~d}$ of life, calves not fed colostrum until $12 \mathrm{~h}$ after birth tended to have lower prevalence of colon mucosa-associated Bifidobacteria spp. and Lactobacillus spp. than those fed colostrum immediately after birth.

Mucosa-associated microorganisms can interact directly with their host, and therefore they are crucial in shaping the host's immune system (Van den Abbeele et al., 2011). We speculated that delayed first colostrum feeding would lead to extensive changes in the mucosa-associated gut microbiota, which might impact gut health and immune function development of calves. Therefore, this study investigated the effect of colostrum feeding time - at 0,6 , or $12 \mathrm{~h}$ after birth - on the taxonomy and diversity of ileum and colon mucosaassociated microbiota at $2 \mathrm{~d}$ of life. Mucosa-associated microbiota were studied, rather than digesta-associated microbiota, due to their potentially direct interactions with the host.

\section{MATERIALS AND METHODS}

\section{Animal Study}

The animal experiment was conducted following the instructions of the Canadian Council of Animal Care (CCAC, 1993), at the Dairy Research and Technology Centre of the University of Alberta. The experiment protocol was approved by the Livestock Care Committee of the University of Alberta (AUP00001595). Holstein heifers and cows were moved to maternity pens around 3 to $10 \mathrm{~d}$ before parturition. Pens were bedded with fresh shavings daily and sterilized between calvings. After the area was cleaned using 1\% iodine, a sterilized iVET birth monitoring device (iVET, Papenburg, Germany) was inserted into the vagina.

Bull calves from singleton births, with BW between 35 and $55 \mathrm{~kg}$, were selected and used in this study. To avoid contact between dams and calves, bulls were removed from the dam immediately after birth, weighed using a calibrated electronic scale (Digi-Star SW300, Digi-Star L.L.C., Fort Atkinson, WI), and transferred to individual pens bedded with clean shavings and fresh straw. Pens were thoroughly disinfected between calves using both Virkon (Vetoquinol N.-A. Inc., Lavaltrie, Québec, Canada) and lime. Bull calves were dried for 10 min using clean towels, and then their navels were dipped with $7 \%$ iodine.

\section{Colostrum Feeding Trial}

Twenty-seven Holstein bull calves born from February to September of 2016 were randomly assigned to 3 treatment groups: fed colostrum at $45 \mathrm{~min}(0 \mathrm{~h}, \mathrm{n}=9)$, $6 \mathrm{~h}(\mathrm{n}=9)$, or $12 \mathrm{~h}(\mathrm{n}=9)$ after birth. A single batch of pooled, heat-treated colostrum containing $62 \mathrm{~g} / \mathrm{L}$ of IgG, provided by the Saskatoon Colostrum Company Ltd. (Saskatoon, Canada), was fed to calves at $7.5 \%$ of birth BW at their respective feeding times. Colostrum was thawed and heated to $39^{\circ} \mathrm{C}$ in a water bath kept at a consistent temperature of $50^{\circ} \mathrm{C}$ before feeding. After heating, colostrum was poured into two 2-L esophageal tubing bottles, transferred to the calf pen in a bucket of warm $\left(\sim 39^{\circ} \mathrm{C}\right)$ water, and tube fed to the calf within 5 min. Twelve hours after their respective colostrum feeding time, calves were fed milk replacer, containing $26 \%$ crude protein and 18\% fat (Excel Pro-Gro Calf Milk Replacer, Grober Nutrition, Cambridge, Canada), at a volume of $2.5 \%$ of birth BW per meal, every $6 \mathrm{~h}$.

\section{Intestinal Tissue Sampling}

All calves were euthanized at $2 \mathrm{~d}$ after birth with a pentobarbital sodium injection (Euthanyl; Vetoquinol, Lavaltrie, Canada) through the jugular catheter, at $0.125 \mathrm{~mL} / \mathrm{kg}$ of BW. Once the calf reached a surgical level of anesthesia, exsanguination was performed, and all visceral organs were removed after ligation of the proximal end of esophagus and distal end of rectum. Following this, 10-cm intestinal segments from each gut region were sampled. The ileum segment was defined as $30 \mathrm{~cm}$ proximal to the ileocecal junction, and the colon segment was defined as $30 \mathrm{~cm}$ distal to the ileocecal junction (Malmuthuge et al., 2015). The contents of each section were squeezed out completely into a $50-\mathrm{mL}$ Falcon tube, and then the tissue was cut open following wash steps using sterile PBS buffer ( $\mathrm{pH} 7.2$ ) until the solution was clean and colorless (approximately 3 to 4 washes). After washing, each intestinal tissue sample was placed into a separate sterile bag and immediately 
snap-frozen in liquid nitrogen and transferred to a $-80^{\circ} \mathrm{C}$ freezer for storage until further analysis.

\section{Microbial DNA Extraction}

Total DNA extraction was performed using the modified repeated bead-beating and column method, as described by $\mathrm{Yu}$ and Morrison (2004). Briefly, approximately $0.2 \mathrm{~g}$ of tissue sample were added to bead-beating tubes and then subjected to bead beating at $5000 \mathrm{rpm}$ for $3 \mathrm{~min}, 2$ times, using BioSpec Mini Beadbeater 8 (BioSpec Products Inc., Bartlesville, OK), followed by column purification using QIAamp Fast DNA Stool Mini Kit (Qiagen, Hilden, Germany). DNA quantity and quality were further assessed using a NanoDrop 1000 Spectrophotometer (NanoDrop Technologies, Wilmington, DE).

\section{Profiling of Ileum and Colon Bacteria Using Amplicon Sequencing}

Amplification of V1 to V3 hypervariable regions of the 16S rRNA gene for amplicon sequencing was performed through a nested PCR-based approach, with an aim of minimizing nonspecific amplifications (Gosiewski et al., 2014). Briefly, the total bacterial fulllength 16S rRNA gene was first enriched through PCR amplification with $27 \mathrm{~F}$ and $1492 \mathrm{R}$ primers, to enrich bacterial 16S rRNA full-length genes in the samples (27F: 5'-AGAGTTTGATCMTGGCTCAG-3'; 1492R: 5'-TACGGYTACCTTGTTACGACTT-3'; Lane, 1991) using the following program: $94^{\circ} \mathrm{C}$ for $30 \mathrm{~s}, 30$ cycles of $58^{\circ} \mathrm{C}$ for $30 \mathrm{~s}, 72^{\circ} \mathrm{C}$ for $100 \mathrm{~s}$ followed by $72^{\circ} \mathrm{C}$ for 7 min. Then, $10 \times$ diluted PCR products were subjected to a second amplification with $27 \mathrm{~F}$ and $515 \mathrm{R}$ primers (27F-CS1F: ACACTGACGACATGGTTCTACAGAGTTTGATCMTGGCTCAG; 515R-CS2R: TACGGTAGCAGAGACTTGGTCTCCGCGGCKGCTGGCAC; Kroes et al., 1999) using the following program: $94^{\circ} \mathrm{C}$ for $30 \mathrm{~s}, 30$ cycles of $62^{\circ} \mathrm{C}$ for $30 \mathrm{~s}, 72^{\circ} \mathrm{C}$ for $1 \mathrm{~min}$, followed by $72^{\circ} \mathrm{C}$ for $7 \mathrm{~min}$. Amplicon DNA with targeted size ( $\sim 500 \mathrm{bp})$ was purified from $1 \%$ agarose gel using QIAEX II gel extraction kit (Qiagen). Quality and quantity of purified PCR products were evaluated using a NanoDrop 1000 (NanoDrop Technologies), to ensure that the concentration of DNA from all samples was higher than $25 \mathrm{ng} / \mu \mathrm{L}$. The amplicons were sequenced at Genome Quebec (McGill University, Montreal, Canada) using Illumina's MiSeq platform (2 $\times 300$ bp; Illumina, San Diego, CA).

\section{Taxonomic Identification}

Sequence data was analyzed using QIIME (Quantitative Insight Into Microbial Ecology) package, version 1.9 (Caporaso et al., 2010). First, low-quality (Phred score $<20)$ and short reads $(<100 \mathrm{bp})$ were filtered out from the demultiplexed raw sequences. Then, chimeric sequences were removed, and the remaining sequences were subjected to operational taxonomic unit (OTU) identification based on $97 \%$ similarity using closed-reference OTU picking function. Taxonomic characterization was performed using the SILVA database (SILVA Release 123, July 2015, Bremen, Germany). Alpha diversity indices (Chao 1, Shannon, and observed species) and Good's coverage were calculated using alpha rarefaction script in QIIME. Principal coordinate analysis of microbial profiles was conducted using UniFrac distance matrices in R (http://www.rstudio.com). Analysis of similarity in $\mathrm{R}$ was used to test the statistical differences among observed microbial profiles based on 2 regions (ileum and colon).

\section{Statistical Analyses}

Data were analyzed using $\mathrm{R}$ version 3.3 .1 and SPSS 22.0 packages (IBM Corp., Armonk, NY). Analyses of Chao 1 and Shannon indices were performed using either one-way ANOVA, when the data satisfied the assumption of homoscedasticity, with multiple comparisons using Fisher's least significant difference procedure, or Welch's ANOVA when the data were heteroscedastic, using a Games-Howell test to conduct multiple comparison among treatments. Effects of colostrum feeding time and gut region on the relative abundance of detected bacterial groups were assessed using Kruskal-Wallis, and Dunn's test was applied to conduct multiple comparisons. Significant difference was declared at $P<0.05$. Spearman's rank correlations were performed between the molar proportion of shortchain fatty acid (SCFA) and the relative abundance of ileum and colon mucosa-associated bacterial genera. Significant correlations were defined as $-0.5>\rho>$ 0.5 , and $P<0.01$, where $\rho$ is defined as the Spearman rank-order correlation coefficient.

\section{Nucleotide Sequence Accession Numbers}

Identified sequences from this study were deposited in the NCBI Sequence Read Archive, under accession numbers SRR7516056 to SRR7516109. 
Table 1. Operational taxonomic units (OTU), sequences, Good's coverage, Chao 1, and Shannon index of ileum and colon mucosa-associated bacterial communities of calves fed colostrum 0,6 , and $12 \mathrm{~h}$ after birth

\begin{tabular}{|c|c|c|c|c|c|}
\hline \multirow[b]{2}{*}{ Location } & \multirow[b]{2}{*}{ Item } & \multicolumn{3}{|c|}{ Time of colostrum intake } & \multirow[b]{2}{*}{ SEM } \\
\hline & & $0 \mathrm{~h}$ & $6 \mathrm{~h}$ & $12 \mathrm{~h}$ & \\
\hline \multirow[t]{5}{*}{ Ileum } & OTU & 330 & 339 & 340 & 17 \\
\hline & Sequences & 38,503 & 37,640 & 36,690 & 1,216 \\
\hline & Good's coverage & 0.978 & 0.978 & 0.979 & 0.001 \\
\hline & Chao 1 & 400.4 & 393.4 & 391.0 & 96 \\
\hline & Shannon index & 4.05 & 4.15 & 4.02 & 0.74 \\
\hline \multirow[t]{5}{*}{ Colon } & OTU & 422 & 540 & 507 & 25 \\
\hline & Sequences & 31,107 & 39,829 & 35,850 & 1,155 \\
\hline & Good's coverage & 0.966 & 0.957 & 0.957 & 0.001 \\
\hline & Chao 1 & 565.0 & 645.8 & 619.9 & 129 \\
\hline & Shannon index & 4.64 & 5.17 & 5.34 & 0.76 \\
\hline
\end{tabular}

\section{RESULTS AND DISCUSSION}

\section{Diversity and Taxonomy of Ileum Mucosa- Associated Microbiota of 2-Day-Old Calves}

Amplicon sequencing generated 1,015,516 high-quality sequences for the ileum mucosa-associated bacteria, with an average of 37,611 sequences per sample. In total, 9,092 OTU (an average of $337 \pm 88$ OTU per sample) were assigned, based on a $97 \%$ nucleotide sequence similarity. The Good's coverage estimates averaged as 0.98 , implying that the current sequencing depth was sufficient to be representative of the microbiota studied (Table 1). No difference was observed in the Chao 1 and Shannon indices among treatments (Table 1), indicating no significant changes in diversity of ileum mucosa-associated microbiota in response to different colostrum feeding times. Principal coordinate analysis showed that ileum mucosa-associated bacterial profiles did not differ among the 3 treatment groups (ANOSIM $\mathrm{R}=0.07, P=0.10$ ) (Figure 1a).

We identified 14 bacteria phyla (defined as relative abundance $>0.01 \%$ in at least 1 sample), and 5 bacteria phyla were detected (relative abundance $>0.1 \%$ and present in more than 5 of the animals per group). Proteobacteria $(57.0 \%)$ was the most predominant phylum, followed by Actinobacteria (23.8\%) and Firmicutes (18.5\%) (Figure 2a). A total of 203 bacterial genera were identified in ileum mucosa-associated bacteria, and 21 genera were detected using the same cut-offs mentioned above. Escherichia-Shigella (52.6\%), Nocardiopsis (13.7\%), and Brevibacterium (10.0\%) were the 3 most abundant genera in the ileum mucosa-associated bacteria of dairy calves at age $2 \mathrm{~d}$ (Figure $2 \mathrm{~b}$ ). As a member of the Escherichia-Shigella genus, a higher proportion of $E$. coli than other bacterial species was identified in the same ileum tissue samples by using quantitative PCR (Fischer et al., 2018). Previous studies have shown that
E. coli is a vitamin K producer (Ramotar et al., 1984), which makes it a key participant in the proliferation of osteoblastic cells and bone homeostasis (Bügel, 2008). It has been suggested that enriched gene levels for vitamin $\mathrm{K}$ synthesis are correlated with high abundance of Escherichia-Shigella in newborn babies (Bäckhed et al., 2015). In addition, E. coli participates in the transportation and phosphorylation of carbohydrates, as well as the regulation of carbohydrate metabolism (Deutscher et al., 2014). We thus speculate that the high prevalence of Escherichia-Shigella genus and likely $E$. coli in the current study might be associated with osteogenesis and carbohydrate metabolism of newborn calves. Increasing evidence demonstrates that some strains of generic E. coli are beneficial to host health, especially when hosts are infected by other pathogens. A recent study discovered that gut colonization of mice by E. coli $\mathrm{O} 21: \mathrm{H}^{+}$prevented wasting of skeletal muscle and fat tissue triggered by Salmonella typhimurium or Burkholderia thailandensis infections (Schieber et al., 2015). Another study demonstrated that E. coli Nissle 1917 could inhibit the proliferation of competing pathogenic Enterobacteriaceae during intestinal inflammation in mice, including commensal E. coli, adherent-invasive E. coli, and Salmonella enterica (Sassone-Corsi et al., 2016). Therefore, it is of interest to further identify the ileum mucosa-associated Escherichia-Shigella, at species or strain level, in order to further illustrate their roles in the health and growth of neonatal calves.

Nocardiopsis, a genus belonging to Actinobacteria phylum, was detected as the second most abundant bacteria in ileum mucosa of calves aged $2 \mathrm{~d}$. Although Nocardiopsis has been identified in neonatal meconium (Osipov et al., 2009) and intestinal mucosa of piglets aged $7 \mathrm{wk}$ (Tajima et al., 2013), the relative abundance of this genus was very low $(0.1 \%)$ in the terminal ileum mucosa of piglets (Tajima et al., 2013). Several strains of Nocardiopsis spp. produce enzymes including 


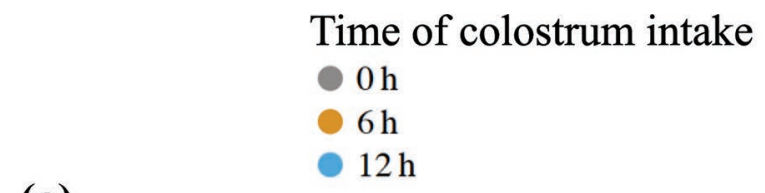

(a)

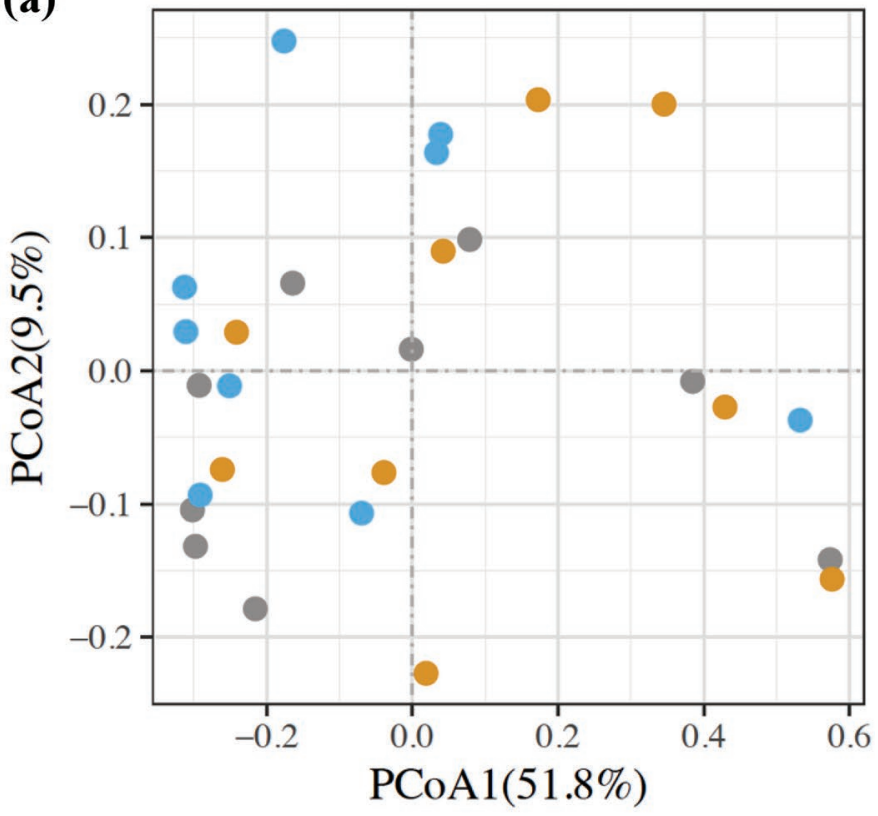

(b)

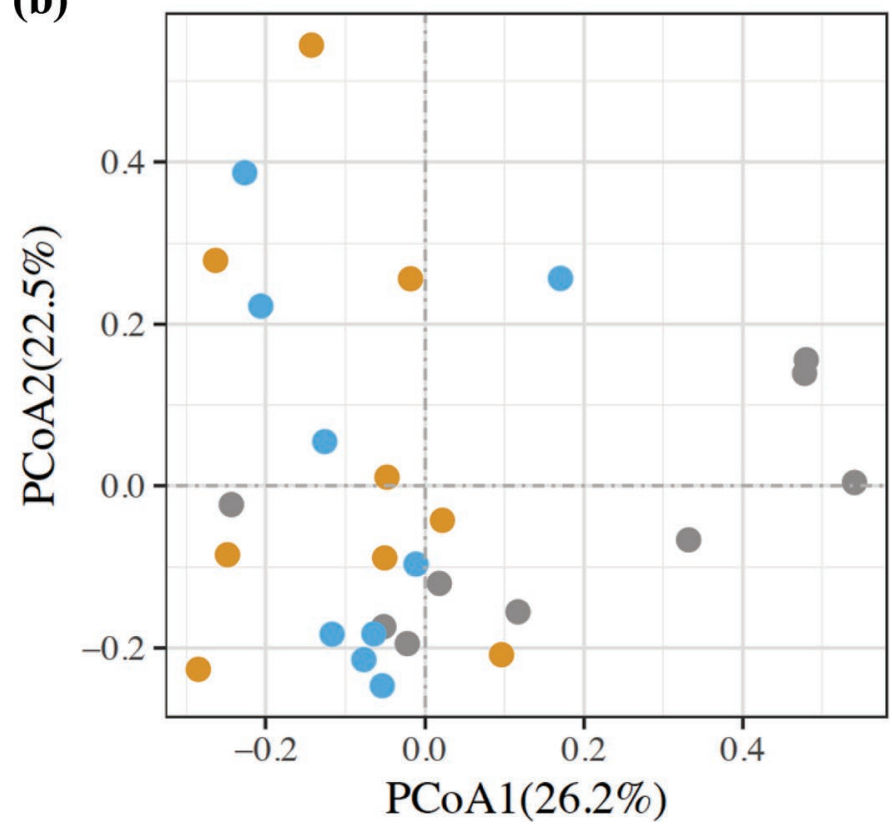

Figure 1. Comparison of (a) ileum and (b) colon mucosa-associated bacterial diversity of calves fed colostrum at 0,6 , and $12 \mathrm{~h}$ after birth with principal coordinate analysis ( $\mathrm{PCoA})$. The $\mathrm{PCoA}$ plot was generated using Bray-Curtis. Colon mucosa-associated bacteria are plotted along the first two principal component axes (PCoA1 and PCoA2). Different colors of points (gray, orange, and blue) indicate time of colostrum intake $(0,6$, and $12 \mathrm{~h}$, respectively). $\alpha$-amylases, xylanases, and cellulases, some of which can act on insoluble polymers, such as glucans and keratin (Bennur et al., 2014), which may be beneficial to host health. Moreover, an antibiotic-producing Nocardiopsis sp. has been isolated from the honeybee gut (Patil et al., 2010). Therefore, the high relative abundance of Nocardiopsis observed in the ileum mucosa-associated microbiota of 2-d-old calves indicates that it may play an important role during early life of neonatal calves. Brevibacterium is another genus belonging to the phylum Actinobacteria. Similar to Nocardiopsis, this bacterial genus has also been found among the duodenal mucosa-associated bacteria of adult humans ( $\mathrm{Li}$ et al., 2018). It has been suggested that Brevibacterium is able to degrade microcystin (de la Cruz et al., 2011), a hepatotoxin potentially derived from contaminated milk or water (Orr et al., 2001) that could cause death in cattle (Mez et al., 1997). Therefore, the existence of Brevibacterium in ileum mucosa-associated bacteria could be helpful to newborn calves in terms of preventing infection by microcystin in raw bovine milk or water. Further isolation and identification of Nocardiopsis and Brevibacterium from the calf gut is needed to verify their colonization and functions in the ileum mucosa of ruminants.

\section{Diversity and Taxonomy of Colon Mucosa- Associated Microbiota of 2-Day-Old Calves}

A total of 961,082 high-quality sequences were generated for colon mucosa-associated microbiota, with an average of 35,595 sequences per sample. These were assigned to a total of 14,129 OTU, with an average of $523 \pm 132$ OTU per sample, based on a $97 \%$ nucleotide sequence similarity (Table 1). Similarly, no difference was observed in Chao 1 index or Shannon index among treatments (Table 1) and principal coordinate analysis plot showed that colon mucosa-associated bacterial profiles did not differ among the 3 treatment groups (ANOSIM $\mathrm{R}=0.06, P=0.12$ ) (Figure $1 \mathrm{~b}$ ).

We identified 10 bacteria phyla and detected 4 in colon mucosa-associated microbiota according to the definition described above, with Firmicutes (67.7\%) being the predominate phylum, followed by Proteobacteria (26.7\%) and Bacteroidetes (4.91\%) (Figure 2a). A total of 154 bacteria genera were identified in colon mucosa-associated microbiota of newborn calves. Similar to the ileum mucosa-associated microbiota, Escherichia-Shigella (25.3\%) was the most predominant genus among the 22 detectable genera in the colon mucosa, followed by Butyricicoccus (19.7\%), Streptococcus (12.5\%), Faecalibacterium (11.0\%), Blautia (7.2\%), and 
(a)

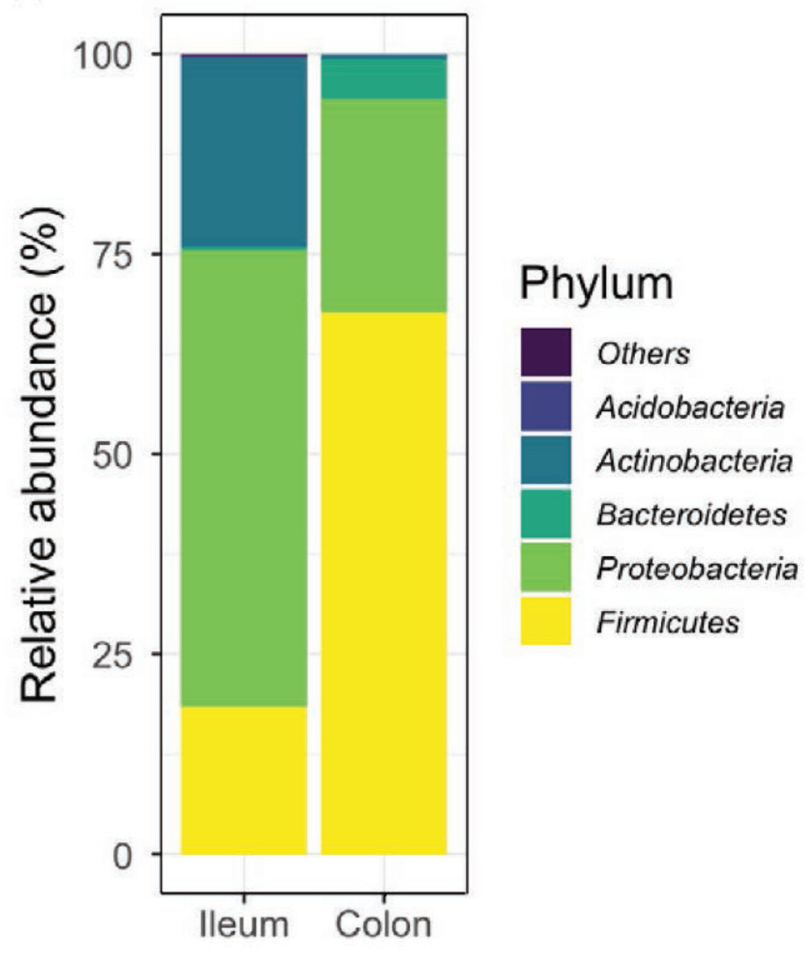

(b)

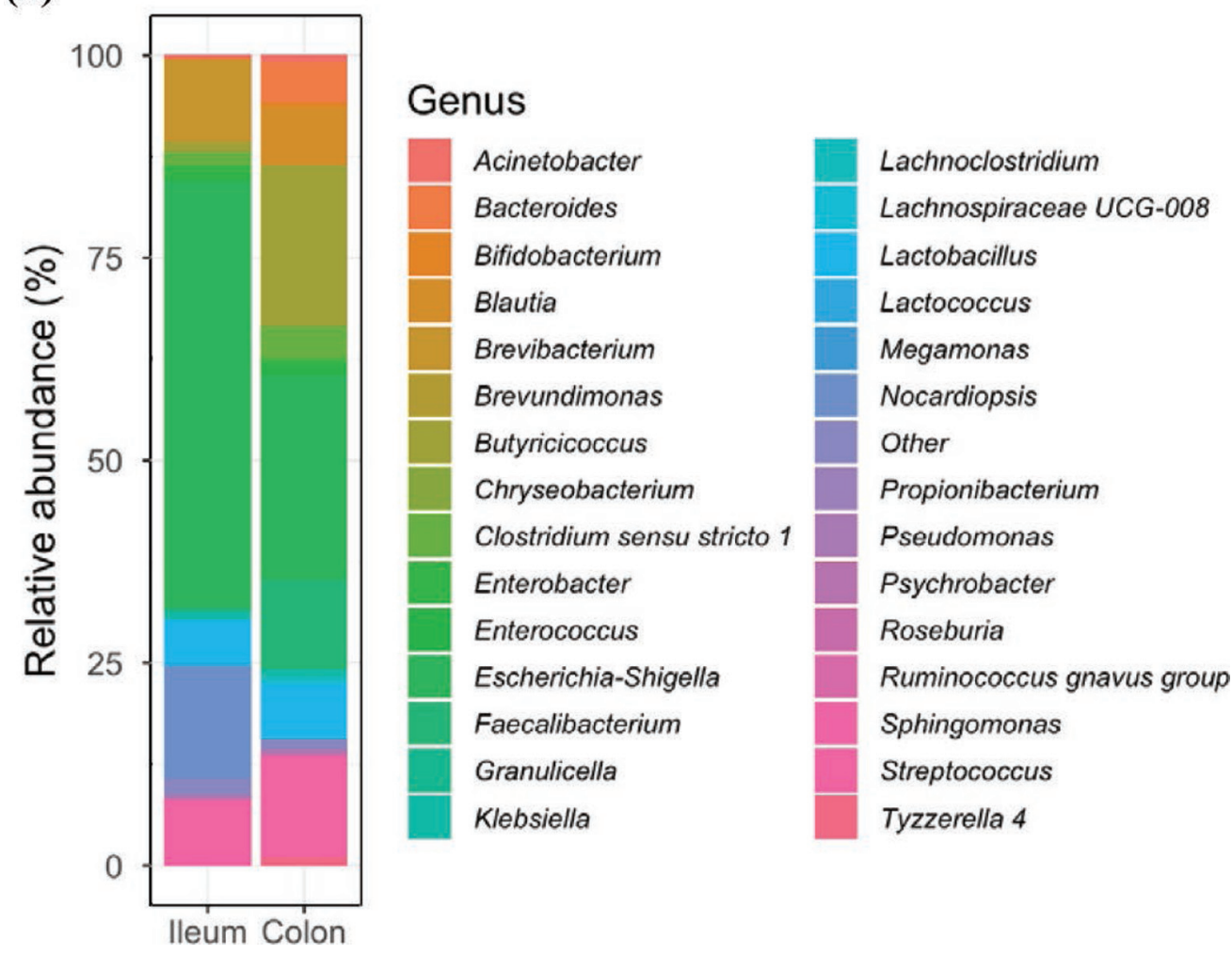

Figure 2. Bacterial composition in ileum and colon mucosa of 2-d-old calves. (a) Bacterial composition at phylum level. Bars represent the relative abundance of the identified bacterial phyla (relative abundance $>0.1 \%$ and present in more than 5 animals in each group) in different regions (ileum and colon) of gut. (b) Bacterial composition at genus level. Bars represent the relative abundance of the identified bacterial genera (relative abundance $>0.1 \%$ and present in more than 5 animals in each group) in different regions (ileum and colon) of gut. 
Lactobacillus (6.6\%; Figure 2b). Our previous study suggested that mucosa-associated microbiota in the hindgut was dominated by Escherichia-Shigella and Bacteroides in calves euthanized within 30 min after birth (Song et al., 2018). The significance of the high prevalence of Escherichia-Shigella in colon mucosa-associated bacteria could be comparable to that observed in ileum mucosa-associated bacteria, suggesting that osteogenesis modulation and carbohydrate metabolism could be among the main host-microbial interactions in ileum and colon mucosa of newborn calves.

Blautia is a genus that belongs to the phylum Firmicutes, which provide energy to their host by degrading complex polysaccharides that cannot be degraded by other gut microorganisms to produce SCFA, mainly acetate, butyrate, and propionate (Biddle et al., 2013). Compared to the ileum, the colon is the main fermentation site before the rumen is developed, which may explain the elevated presence of Blautia found in this study. Different Blautia species have specialized functions, such as $\mathrm{H}_{2}$ consumption by Blautia hydrogenotrophica during acetogenesis (Bernalier et al., 1996), and $\alpha$-(1,6)-galactosidase activity in Ruminococcus gnavus, which is also proposed to fall within the Blautia cluster but has not been renamed (Cervera-Tison et al., 2012; Ludwig et al., 2015). Thus, the high relative abundance of Blautia in colon mucosa-associated bacteria in 2-dold calves might extensively contribute to nutrient (milk) assimilation and SCFA production to provide energy for the host calf.

Genera Butyricicoccus, Faecalibacterium, and Lactobacillus belong to the phylum Firmicutes, which are known to produce butyrate (Louis and Flint, 2017), an SCFA critical to maintaining host gut health by serving as a major source of energy to the colonic mucosa. Butyrate is also an important regulator of gene expression, inflammation, differentiation, and apoptosis in host intestinal epithelial cells (Scheppach and Weiler, 2004; Pajak et al., 2007; Hamer et al., 2008). One study suggested that Butyricicoccus pullicaecorum strengthens epithelial barrier function by increasing the transepithelial resistance in mice (Eeckhaut et al., 2013). It has also been reported that $B$. pullicaecorum can protect the gut from pathogens and prevent necrotic enteritis in broilers (Eeckhaut et al., 2016). These results indicate that the high relative abundance of Butyricicoccus in colon mucosa-associated microbiota of 2-d-old calves might be essential to improving barrier function and defending the gut from harmful bacteria. Faecalibacterium prausnitzii also produces formate, D-lactate, and other metabolites in addition to butyrate, which could participate in the suppression of gut inflammation, indicating its role in modifying the gut barrier
(Sokol et al., 2008). Similarly, Lactobacilli can interact intensively with the intestinal barrier and act on the gut immune system (Gourbeyre et al., 2011). All these findings suggest that commensal bacteria may play a critical role in maintaining gut health by modulating the gut immune system.

\section{Correlation Between Molar Proportion of SCFA and the Relative Abundance of Mucosa-Associated Bacteria in Ileum and Colon}

Intestinal fermentation products, namely SCFA, play key roles in protecting epithelial cells from inflammation (Hamer et al., 2008) and infection by enteropathogens (Fukuda et al., 2011). To explore the potential interaction between intestinal fermentation products and mucosa-associated bacterial composition, the molar proportions of SCFA (acetate and propionate) and the relative abundance of ileum and colon mucosa-associated bacterial genera were investigated separately, based on Spearman's rank correlations. The data set of the molar proportion of SCFA was obtained from Song (2018).

In general, more correlations were observed between the molar proportion of SCFA and mucosa-associated bacteria in the ileum (Figure 3a) than between SCFA and mucosa-associated bacteria in the colon (Figure $3 b)$. Of note, the molar proportion of acetate negatively correlated with the relative abundance of Psychrobac$\operatorname{ter}(\rho=-0.61, P<0.05)$ and Subdoligranulum $(\rho=$ $-0.54, P<0.05)$, while that of propionate negatively correlated with the relative abundance of EscherichiaShigella $(\rho=-0.57, P<0.05)$ in the ileum mucosa. The relative abundance of Psychrobacter has been observed to be higher in cows with Johne's disease compared with healthy ones (Kaevska et al., 2016). On the other hand, species belonging to Subdoligranulum produce butyrate (Eeckhaut et al., 2011), the production of which requires acetate as a key intermediate (De Vuyst and Leroy, 2011), and therefore the negative correlation between its abundance and acetate proportion can be expected. The identified relationships suggested that SCFA might be crucial to protecting the ileum epithelium from potential pathogen invasion and maintaining normal ileum function.

We further found that the molar proportion of acetate positively correlated with the relative abundance of Lactobacillus $(\rho=0.54, P<0.05)$, and the molar proportion of propionate positively correlated with the relative abundance of Lachnospiracea FSC020 in colon mucosa $(\rho=0.51, P<0.05)$. In addition, the molar proportion of both acetate $(\rho=0.54, P<0.05)$ and propionate $(\rho=0.53, P<0.05)$ positively correlated 
with the relative abundance of Bacteroides in colon mucosa. It has been proven that acetate produced by colon mucosa-associated Bacteroides thetaiotaomicron is used by $F$. prausnitzii to produce butyrate in rats (Wrzosek et al., 2013). On the other hand, propionate in the colon is essential to control colonic inflammation through inducing the differentiation of regulatory
T cells in mice (Smith et al., 2013). Our findings on the positive relationships between those 3 bacteria genera (Lactobacillus, Lachnospiracea FSC020, and Bacteroides) and acetate and propionate illustrate the potential major acetate and propionate producers in colon mucosa-associated microbiota of newborn calves; however, their interactions with other bacteria, as well (a)
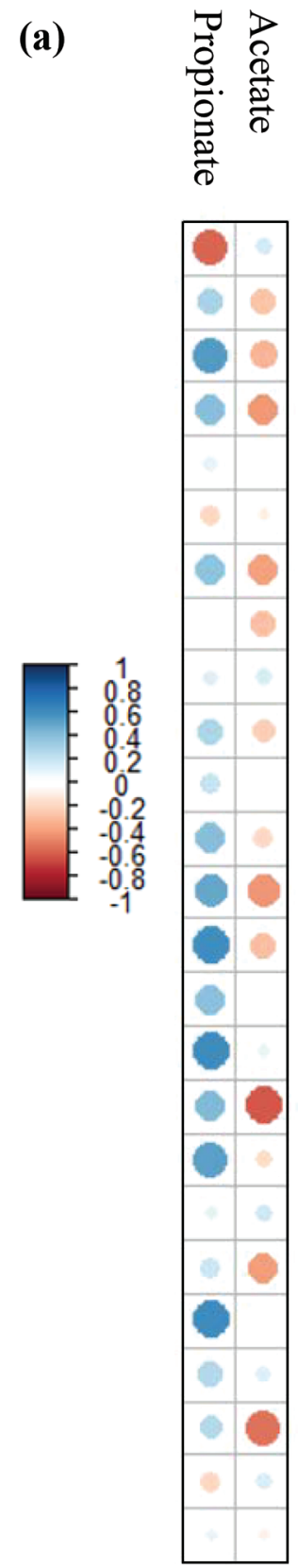

Escherichia-Shigella

Nocardiopsis

Brevibacterium

Streptococcus

Lactobacillus

Clostridium_sensu_stricto_I

Butyricicoccus

Klebsiella

Sarcina

Lactococcus

Enterococcus

Faecalibacterium

Acinetobacter

Pseudomonas

Burkholderia-Paraburkholde

Sphingomonas

Psychrobacter

Blautia

Clostridium_sensu_stricto_2

Buttiauxella

Mesorhizobium

Bacillus

Subdoligranulum

Bacteroides

Others (b)
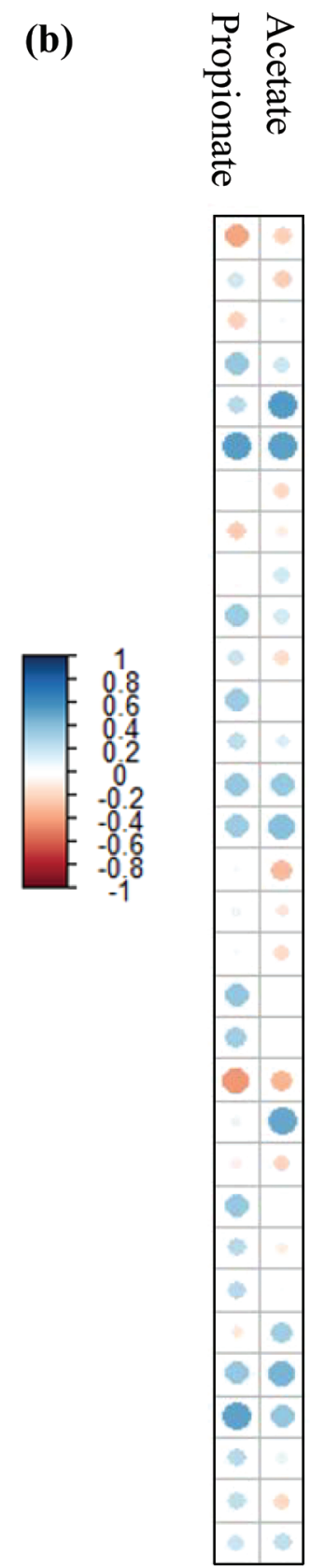

Escherichia-Shigella

Butyricicoccus

Streptococcus

Faecalibacterium

Lactobacillus

Bacteroides

Blautia

Clostridium sensu stricto 1

Klebsiella

Lachnospiraceae UCG-008

Tyzzerella 4

Dorea

Enterococcus

Acinetobacter

Bifidobacterium

Clostridium sensu stricto 2

Lachnospiraceae NK4A136

Sarcina

Ruminococcus 1

Roseburia

Enterobacter

Chryseobacterium

Lachnospiraceae UCG-004

Ruminococcus torques

Lachnoclostridium

Eubacterium rectale

Psychrobacter

Pseudomonas

Lachnospiraceae FCS020

Eubacterium hallii

Eubacterium oxidoreducens

Others

Figure 3. Relationship between molar proportions of short-chain fatty acids (SCFA) and (a) ileum and (b) colon mucosa-attached bacteria. Significant correlations were found between the molar proportions of SCFA and the relative abundance of ileum mucosa-associated EscherichiaShigella, Brevibacterium, Pseudomonas, Sphingomonas, Psychrobacter, Blautia, Mesorhizobium, and Subdoligranulum, and colon mucosa-associated Lactobacillus, Bacteroides, and Lachnospiraceae FCS020 by Spearman's rank correlation $(P<0.05)$. 
as their roles in host immune function, need further investigation.

\section{Shift in Ileum and Colon Mucosa-Associated Microbiota in Response to Delayed First Colostrum Feeding}

Delayed time of first colostrum feeding did not affect the relative abundance of ileum mucosa-associated bacteria at the phylum level (Table 2). However, calves fed colostrum at $12 \mathrm{~h}$ after birth had higher $(0.89 \%)$ relative abundance of Enterococcus than those under the other 2 treatments $(0.35 \%$ for $0 \mathrm{~h}$ and $0.04 \%$ for $6 \mathrm{~h}$ after birth; $P=0.01$; Table 2). Calves fed colostrum $6 \mathrm{~h}$ after birth had a higher relative abundance of Brevibacterium (15.4\%) than those fed colostrum at $0(8.80 \%)$ or $12 \mathrm{~h}(5.88 \%)$ after birth $(P=0.04$; Table 2$)$. Relative abundance of Streptococcus $(P=0.06)$ tended to be higher in calves fed colostrum $12 \mathrm{~h}$ after birth (14.0\%) compared with those fed colostrum at $0(5.45 \%)$ or $6 \mathrm{~h}$ $(4.79 \%)$ after birth $(P=0.06$; Table 2$)$. Delayed first colostrum meal did not affect the relative abundance of other genera in ileum mucosa. Similarly, delayed colostrum feeding did not affect bacterial abundance in the colon mucosa at a phylum level (Table 3). Relative abundance of Ruminococcus gnavus was higher in calves fed colostrum $6 \mathrm{~h}(0.21 \%)$ and $12 \mathrm{~h}(0.29 \%)$ after birth than those fed immediately after birth $(0.08 \% ; P=$ 0.01; Table 3). The relative abundance of Lactobacillus tended to be lower in calves fed colostrum at $12 \mathrm{~h}$ (1.90\%) after birth compared with those fed colostrum at $0 \mathrm{~h}(9.95 \%)$ and $6 \mathrm{~h}(7.92 \%)$ after birth $(P=0.06$; Table 3), while that of Faecalibacterium tended to be higher in calves fed colostrum at $6 \mathrm{~h}(16.6 \%)$ and $12 \mathrm{~h}$ (15.4\%) after birth compared with those fed colostrum immediately after birth $(1.17 \% ; P=0.07$; Table 3$)$. Delaying the first colostrum meal did not affect the relative abundance of any other genus in the colon mucosa.

Fischer et al (2018) reported that delaying colostrum feeding up to $12 \mathrm{~h}$ after birth decreased the passive transfer of IgG in calves. An early study indicated that delayed colostrum feeding might result in the transepithelial migration of pathogens prior to gut closure, due to low IgG absorption in calves (Stott et al., 1979). Certain levels of serum IgG are needed to protect neonates against group B streptococci (Baker and Kasper, 1976) and adults against Shigella-induced shigellosis (Cohen et al., 1991). Numerous streptococci and sev-

Table 2. Ileum mucosa-associated bacterial composition at phylum and genus level of calves fed colostrum at 0,6 , and $12 \mathrm{~h}$ after birth

\begin{tabular}{|c|c|c|c|c|c|}
\hline \multirow[b]{2}{*}{ Phylum } & \multirow[b]{2}{*}{ Genus } & \multicolumn{3}{|c|}{ Time of colostrum intake } & \multirow[b]{2}{*}{ SEM } \\
\hline & & $0 \mathrm{~h}$ & $6 \mathrm{~h}$ & $12 \mathrm{~h}$ & \\
\hline \multirow[t]{9}{*}{ Proteobacteria } & & 60.8 & 50.7 & 59.1 & 4.56 \\
\hline & Escherichia-Shigella & 56.1 & 46.8 & 55.0 & 4.60 \\
\hline & Enterobacter & 1.42 & 1.46 & 1.50 & 0.20 \\
\hline & Klebsiella & 0.84 & 0.88 & 0.90 & 0.34 \\
\hline & Acinetobacter & 0.25 & 0.42 & 0.29 & 0.13 \\
\hline & Pseudomonas & 0.55 & 0.16 & 0.39 & 0.10 \\
\hline & Brevundimonas & 0.16 & 0.04 & 0.27 & 0.07 \\
\hline & Sphingomonas & 0.01 & 0.17 & 0.10 & 0.04 \\
\hline & Psychrobacter & 0.35 & 0.09 & 0.17 & 0.06 \\
\hline \multirow[t]{9}{*}{ Firmicutes } & & 20.7 & 12.6 & 22.3 & 2.62 \\
\hline & Streptococcus & 5.45 & 4.79 & 14.0 & 2.64 \\
\hline & Lactobacillus & 5.96 & 6.06 & 4.31 & 1.53 \\
\hline & Clostridium sensu stricto 1 & 4.94 & 0.15 & 0.17 & 1.27 \\
\hline & Butyricicoccus & 1.88 & 0.43 & 0.90 & 0.49 \\
\hline & Lactococcus & 0.61 & 0.38 & 0.44 & 0.13 \\
\hline & Blautia & 0.13 & 0.19 & 0.05 & 0.04 \\
\hline & Enterococcus & $0.35^{\mathrm{b}}$ & $0.04^{\mathrm{b}}$ & $0.89^{\mathrm{a}}$ & 0.18 \\
\hline & Faecalibacterium & 0.03 & 0.13 & 1.08 & 0.26 \\
\hline \multirow[t]{4}{*}{ Actinobacteria } & & 17.9 & 35.4 & 17.7 & 4.53 \\
\hline & Nocardiopsis & 9.51 & 20.0 & 11.6 & 2.93 \\
\hline & Brevibacterium & $8.80^{\mathrm{b}}$ & $15.4^{\mathrm{a}}$ & $5.88^{\mathrm{b}}$ & 2.64 \\
\hline & Propionibacterium & 0.10 & 0.08 & 0.36 & 0.06 \\
\hline \multirow[t]{2}{*}{ Bacteroidetes } & & 0.40 & 0.51 & 0.39 & 0.12 \\
\hline & Bacteroides & 0.03 & 0.16 & 0.16 & 0.06 \\
\hline \multirow{3}{*}{ Acidobacteria } & & 0.04 & 0.30 & 0.05 & 0.07 \\
\hline & Granulicella & 0.04 & 0.30 & 0.05 & 0.07 \\
\hline & Others & 2.50 & 1.86 & 1.48 & 0.36 \\
\hline
\end{tabular}

${ }^{\mathrm{a}, \mathrm{b}}$ Means within a row with different superscripts differ $(P<0.05)$. 
Table 3. Colon mucosa-associated bacterial composition at phylum and genus level of calves fed colostrum at 0,6 , and $12 \mathrm{~h}$ after birth

\begin{tabular}{|c|c|c|c|c|c|}
\hline \multirow[b]{2}{*}{ Phylum } & \multirow[b]{2}{*}{ Genus } & \multicolumn{3}{|c|}{ Time of colostrum intake } & \multirow[b]{2}{*}{ SEM } \\
\hline & & $0 \mathrm{~h}$ & $6 \mathrm{~h}$ & $12 \mathrm{~h}$ & \\
\hline \multirow[t]{15}{*}{ Firmicutes } & & 65.7 & 71.1 & 66.4 & 2.84 \\
\hline & Streptococcus & 25.5 & 3.85 & 8.04 & 3.48 \\
\hline & Butyricicoccus & 15.0 & 19.7 & 24.3 & 2.33 \\
\hline & Lactobacillus & 9.95 & 7.92 & 1.90 & 1.66 \\
\hline & Blautia & 6.02 & 9.30 & 6.50 & 1.26 \\
\hline & Clostridium sensu stricto 1 & 3.20 & 6.38 & 2.25 & 1.33 \\
\hline & Lachnospiraceae UCG-008 & 0.36 & 0.81 & 0.58 & 0.09 \\
\hline & Faecalibacterium & 1.17 & 16.6 & 15.4 & 3.19 \\
\hline & Tyzzerella 4 & 0.77 & 0.99 & 1.30 & 0.20 \\
\hline & Enterococcus & 0.64 & 0.89 & 1.63 & 0.22 \\
\hline & Lachnoclostridium & 0.44 & 0.63 & 0.43 & 0.13 \\
\hline & Ruminococcus gnavus & $0.08^{\mathrm{b}}$ & $0.21^{\mathrm{a}}$ & $0.29^{\mathrm{a}}$ & 0.03 \\
\hline & Megamonas & 0.07 & 0.24 & 0.01 & 0.07 \\
\hline & Lachnospiraceae UCG-006 & 0.04 & 0.05 & 0.03 & 0.01 \\
\hline & Roseburia & 0.05 & 0.29 & 0.14 & 0.05 \\
\hline \multirow[t]{7}{*}{ Proteobacteria } & & 31.0 & 21.3 & 27.7 & 2.97 \\
\hline & Escherichia-Shigella & 27.2 & 21.7 & 26.9 & 2.70 \\
\hline & Klebsiella & 0.43 & 0.55 & 1.57 & 0.29 \\
\hline & Acinetobacter & 2.31 & 0.04 & 0.11 & 0.51 \\
\hline & Pseudomonas & 1.40 & 0.06 & 0.09 & 0.45 \\
\hline & Enterobacter & 0.67 & 0.64 & 1.13 & 0.14 \\
\hline & Psychrobacter & 0.16 & 0.19 & 0.12 & 0.06 \\
\hline \multirow[t]{3}{*}{ Bacteroidetes } & & 1.46 & 7.50 & 5.77 & 2.00 \\
\hline & Bacteroides & 1.06 & 7.46 & 6.08 & 2.10 \\
\hline & Chryseobacterium & 0.55 & 0.19 & 0.12 & 0.09 \\
\hline \multirow[t]{3}{*}{ Actinobacteria } & & 1.81 & 0.08 & 0.06 & 0.49 \\
\hline & Bifidobacterium & 1.81 & 0.04 & 0.01 & 0.50 \\
\hline & Others & 1.12 & 1.27 & 1.07 & 0.13 \\
\hline
\end{tabular}

${ }^{\mathrm{a}, \mathrm{b}}$ Means within a row with different superscripts differ $(P<0.05)$.

eral enterococci have been reported as opportunistic pathogens that can cause infections in immune-compromised hosts (Krzyściak et al., 2013; Gao et al., 2018). We speculate that the increased relative abundance of Enterococcus and Streptococcus in calves fed colostrum $12 \mathrm{~h}$ after birth could also be associated with reduced IgG transfer, which may increase the probability of microorganism invasion of ileum epithelia (Stott et al., 1979). These results suggest that early nutrition is a key contributor to the modulation of host immune function and gut microbiota. Moreover, it should be noted that increased relative abundance of Enterococcus and Streptococcus could enhance gut permeability through increased D-lactic acid production, which could in turn lead to inflammation and immune activation (Sheedy et al., 2009). Therefore, delaying colostrum feeding to $12 \mathrm{~h}$ after birth might result in an elevated risk of D-lactic acidosis.

A higher relative abundance of Faecalibacterium in the colon mucosa was observed in calves fed colostrum at 6 and $12 \mathrm{~h}$ after birth. As a butyrate producer, Faecalibacterium was reported to be negatively correlated to diarrhea in 7-wk-old calves (Oikonomou et al., 2013) and has been recommended as a probiotic to reduce the incidence of diarrhea in newborn calves (Foditsch et al., 2014). It has also been reported that $F$. prausnitzii exhibited anti-inflammatory effects by reducing IL-12 and elevating IL-10 colonic concentrations among patients with Crohn's disease (Sokol et al., 2008). Some studies suggest that IL-10 could enhance IgG4 production (Fiorentino et al., 1991), an important class of IgG antibody that is needed to maintain normal immunity (Aalberse et al., 1983). However, others suggest that F. prausnitzii might play a pro-inflammatory role (Hansen et al., 2012) or have no direct connection with the disease (Jia et al., 2010). Therefore, the increased Faecalibacterium observed in calves fed colostrum 6 and $12 \mathrm{~h}$ after birth might represent a pro-inflammatory role due to decreased IgG transfer. It could also be possible that the host responded to the decreased IgG transfer by inducing a proliferation of Faecalibacterium, in order to maintain normal immunity. The effect of time delay in colostrum feeding on the change of relative abundance of mucosa-associated Faecalibacterium and the underlying mechanisms in calves still needs to be investigated.

Pasteurization has been proved to be an effective method to prevent microbial contamination in fresh colostrum, by eliminating potential pathogens such as 
Mycoplasma bovis, Listeria monocytogenes, Escherichia coli O157:H7, and Salmonella enteritidis (Godden et al. 2006). Additionally, our previous study proved that feeding pasteurized colostrum enhanced Bifidobacterium and inhibited E. coli colonization in the ileal (Malmuthuge et al. 2015) and colonic (Song et al., 2019) mucosa of calves during the first $12 \mathrm{~h}$ after birth, suggesting that feeding pasteurized colostrum is more beneficial to the gut health of newborn calves than nonpasteurized colostrum. Therefore, the objective of the current study was to investigate how delayed first colostrum feeding affects the mucosa-associated microbiota within $51 \mathrm{~h}$ of birth, using the pasteurized colostrum recommended in our earlier studies. Although not compared in the current study, we speculated that feeding nonpasteurized colostrum might have different or more prominent effects on mucosa-associated bacteria of newborn calves, compared with the relatively minor differences as observed in this study when pasteurized colostrum was used. Considering that feeding unpasteurized colostrum is also a common practice in calf-rearing systems, future study is needed on how delay in feeding unpasteurized colostrum affects mucosa-associated bacteria and gut health in newborn calves.

Contamination from DNA extraction kits (Mohammadi et al., 2005) as well as from sequencing (Schmieder and Edwards, 2011) has been recognized as a serious concern for the quality of the data used in downstream analysis. These contaminations have still more critical impact on results obtained from samples such as biofluid (Karstens et al., 2018) or samples from neonates (Minich et al., 2018), which contain a low microbial biomass (Salter et al., 2014). We therefore included negative controls for both $\mathrm{PCR}$ and $\mathrm{qPCR}$, and the results confirmed that no contamination had been introduced into the master mix or into samples during sample processing. We didn't use positive control, since it has been proved that calf gut is colonized by bacteria at $6 \mathrm{~h}$ and $12 \mathrm{~h}$ after birth (Malmuthuge et al., 2015; Song et al., 2019) as well as $24 \mathrm{~h}$ after birth (Rey et al., 2014). However, we did not include negative control for DNA extraction, which could be a limitation of the current study. Another potential limitation is that a nested PCR approach was used, which is common to amplify the gene targets from samples with low copy numbers of targets (Higuchi et al., 1993). This approach has been intensively used to investigate neonatal microbiota by others (Wall et al., 2008; Kostric et al., 2018), and we also applied this approach to illustrate the profiles of mucosa-associated bacteria in neonatal calves (Malmuthuge et al., 2015; Song et al., 2018, 2019). It should be noted that bias might be introduced to the mucosa-associated bacterial population we profiled us- ing nested PCR, as there is a substantial risk of carryover contamination due to an additional manipulation of amplification products (Niederhauser et al., 1994). However, we could not amplify the targeted amplicons from all samples without the nested PCR approach, as it is easy to fail to amplify bacteria from tissue DNA in which host DNA is the most abundant. Therefore, more specific and sensitive PCR methods for low-microbial biomass or tissue samples (or both) need to be developed to eliminate potential bias during analysis.

\section{CONCLUSIONS}

This is the first study to investigate the shift among ileum and colon mucosa-associated microbiota in 2-d-old calves in response to delayed intake of first colostrum. We did not detect changes in the relative abundance of many bacterial taxa across treatments, most likely because the calves were well managed in the current study by feeding heat-treated colostrum and milk replacer every $6 \mathrm{~h}$ after the first feeding, which could reduce the incidence of pathogenesis, as well as ensure sufficient nutrition supply. It could be anticipated that in practice, when either feeding regimen or environmental conditions are not as well controlled, or when non-pasteurized colostrum is fed, delayed feeding of first colostrum could have a more prominent influence on intestinal mucosa-associated bacteria. Nevertheless, SCFA might play a role in the differentiation of ileum and colon immune functions, and its interaction with mucosa-associated bacteria and the intestinal epithelium in neonatal calf merits further investigation. On the other hand, the current study lasted for only $2 \mathrm{~d}$, during which the high individual variability of intestinal microbial composition in calves might interfere with or even mask the effects of delayed colostrum feeding during statistical analysis. Further study is needed to test the long-term effects of delayed colostrum feeding on the shift in mucosa-associated gut microbiota. Additionally, although we observed a shift in the relative abundance of commensal bacteria genera, including Enterococcus, Streptococcus, Lactobacillus, and Faecalibacterium, due to delayed feeding of first colostrum, the related mechanisms are still unclear. Further research using metagenomic analysis is needed, to better interpret the observed shift of microbiota in response to delayed colostrum feeding.

\section{ACKNOWLEDGEMENTS}

The authors thank the staff of the Dairy Research and Technology Centre (University of Alberta, Canada) for their assistance with the animal experiment, as well as 
M. Zhou and Y. Chen (University of Alberta) for their assistance with data analysis. This project was funded by Alberta Livestock and Meat Agency Ltd. (Edmonton, Canada; 2015B013R), Alberta Milk (Edmonton, Canada), the Saskatoon Colostrum Co. Ltd. (Saskatoon, Canada), the Natural Sciences and Engineering Research Council of Canada (Ottawa, Canada), and the China Scholarship Council (Beijing, China).

\section{REFERENCES}

Aalberse, R. C., R. van der Gaag, and J. van Leuwen. 1983. Serologic aspects of IgG4 antibodies. I. Prolonged immunization results in an IgG4 restricted response. J. Immunol. 130:722-726.

Bäckhed, F., J. Roswall, Y. Peng, Q. Feng, H. Jia, P. KovatchevaDatchary, Y. Li, Y. Xia, H. Xie, H. Zhong, M. T. Khan, J. Zhang, J. Li, L. Xiao, J. Al-Aama, D. Zhang, Y. S. Lee, D. Kotowska, C. Colding, V. Tremaroli, Y. Yin, S. Bergman, X. Xu, L. Madsen, K. Kristiansen, J. Dahlgren, and J. Wang. 2015. Dynamics and stabilization of the human gut microbiome during the first year of life. Cell Host Microbe 17:690-703.

Baker, C. J., and D. L. Kasper. 1976. Correlation of maternal antibody deficiency and susceptibility to neonatal group B streptococcal infection. N. Engl. J. Med. 294:753-756.

Baldwin, R. L. VI, K. R. McLeod, J. L. Klotz, and R. N. Heitmann. 2004. Rumen development, intestinal growth and hepatic metabolism in the pre- and postweaning ruminant. J. Dairy Sci. 87:E55E65.

Bendixen, E., M. Danielsen, K. Hollung, E. Gianazza, and I. Miller. 2011. Farm animal proteomics-A review. J. Proteomics 74:282293.

Bennur, T., A. R. Kumar, S. Zinjarde, and V. Javdekar. 2014. Nocardiopsis species as potential sources of diverse and novel extracellular enzymes. Appl. Microbiol. Biotechnol. 98:9173-9185.

Bernalier, A., A. Willems, M. Leclerc, V. Rochet, and M. D. Collins. 1996. Ruminococcus hydrogenotrophicus sp. nov., a new $\mathrm{H}_{2} / \mathrm{CO}_{2-}$ utilizing acetogenic bacterium isolated from human feces. Arch. Microbiol. 166:176-183.

Biddle, A., L. Stewart, J. Blanchard, and S. Leschine. 2013. Untangling the genetic basis of fibrolytic specialization by Lachnospiraceae and Ruminococcaceae in diverse gut communities. Diversity (Basel) 5:627-640.

Bügel, S. 2008. Vitamin K and bone health in adult humans. Vitam. Horm. 78:393-416.

Caporaso, J. G., J. Kuczynski, J. Stombaugh, K. Bittinger, F. D. Bushman, E. K. Costello, N. Fierer, A. G. Peña, J. K. Goodrich, J. I. Gordon, G. A. Huttley, S. T. Kelley, D. Knights, J. E. Koenig, R. E. Ley, C. A. Lozupone, D. McDonald, B. D. Muegge, M. Pirrung, J. Reeder, J. R. Sevinsky, P. J. Turnbaugh, W. A. Walters, J. Widmann, T. Yatsunenko, J. Zaneveld, and R. Knight. 2010. QIIME allows analysis of high-throughput community sequencing data. Nat. Methods 7:335-336.

CCAC (Canadian Council on Animal Care). 1993. Guide to the care and use of experimental animals. Canadian Council on Animal Care, Ottawa, Ontario, Canada.

Cervera-Tison, M., L. E. Tailford, C. Fuell, L. Bruel, G. Sulzenbacher, B. Henrissat, J. G. Berrin, M. Fons, T. Giardina, and N. Juge. 2012. Functional analysis of family GH36 $\alpha$-galactosidases from Ruminococcus gnavus E1: Insights into the metabolism of a plant oligosaccharide by a human gut symbiont. Appl. Environ. Microbiol. 78:7720-7732.

Cohen, D., M. S. Green, C. Block, R. Slepon, and I. Ofek. 1991. Prospective study of the association between serum antibodies to lipopolysaccharide $\mathrm{O}$ antigen and the attack rate of shigellosis. J. Clin. Microbiol. 29:386-389.

de la Cruz, A., A. M. G. Antoniou, A. Hiskia, M. Pelaez, W. Song, K. E. O'Shea, X. He, and D. D. Dionysiou. 2011. Can we effectively degrade microcystins?-Implications on human health. Anticancer Agents Med. Chem. 11:19-37.

De Vuyst, L., and F. Leroy. 2011. Cross-feeding between bifidobacteria and butyrate-producing colon bacteria explains bifdobacterial competitiveness, butyrate production, and gas production. Int. J. Food Microbiol. 149:73-80.

Deutscher, J., F. M. D. Aké, M. Derkaoui, A. C. Zébré, T. N. Cao, H. Bouraoui, T. Kentache, A. Mokhtari, E. Milohanic, and P. Joyet. 2014. The bacterial phosphoenolpyruvate:carbohydrate phosphotransferase system: Regulation by protein phosphorylation and phosphorylation-dependent protein-protein interactions. Microbiol. Mol. Biol. Rev. 78:231-256.

Eeckhaut, V., F. V. Immerseel, S. Croubels, S. D. Baere, F. Haesebrouck, R. Ducatelle, P. Louis, and P. Vandamme. 2011. Butyrate production in phylogenetically diverse Firmicutes isolated from the chicken caecum. Microb. Biotechnol. 4:503-512.

Eeckhaut, V., K. Machiels, C. Perrier, C. Romero, S. Maes, B. Flahou, M. Steppe, F. Haesebrouck, B. Sas, R. Ducatelle, S. Vermeire, and F. V. Immerseel. 2013. Butyricicoccus pullicaecorum in inflammatory bowel disease. Gut 62:1745-1752.

Eeckhaut, V., J. Wang, A. V. Parys, F. Haesebrouck, M. Joossens, G. Falony, J. Raes, R. Ducatelle, and F. V. Immerseel. 2016. The probiotic butyricicoccus pullicaecorum reduces feed conversion and protects from potentially harmful intestinal microorganisms and necrotic enteritis in broilers. Front. Microbiol. 7:1416.

Fiorentino, D. F., A. Zlotnik, T. R. Mosmann, M. Howard, and A. O'garra. 1991. IL-10 inhibits cytokine production by activated macrophages. J. Immunol. 147:3815-3822.

Fischer, A. J., Y. Song, Z. He, D. M. Haines, L. L. Guan, and M. A. Steele. 2018. Effect of delaying colostrum feeding on passive transfer and intestinal bacterial colonization in neonatal male Holstein calves. J. Dairy Sci. 101:3099-3109.

Foditsch, C., T. M. A. Santos, A. G. V. Teixeira, R. V. V. Pereira, J. M. Dias, N. Gaeta, and R. C. Bicalho. 2014. Isolation and characterization of Faecalibacterium prausnitzii from calves and piglets. PLoS One 9:e116465.

Fukuda, S., H. Toh, K. Hase, K. Oshima, Y. Nakanishi, K. Yoshimura, T. Tobe, J. M. Clarke, D. L. Topping, T. Suzuki, and T. D. Taylor. 2011. Bifidobacteria can protect from enteropathogenic infection through production of acetate. Nature 469:543-547.

Gao, W., B. P. Howden, and T. P. Stinear. 2018. Evolution of virulence in Enterococcus faecium, a hospital-adapted opportunistic pathogen. Curr. Opin. Microbiol. 41:76-82.

Godden, S., S. McMartin, J. Feirtag, J. Stabel, R. Bey, S. Goyal, L. Metzger, J. Fetrow, S. Wells, and H. Chester-Jones. 2006. Heattreatment of bovine colostrum. II: Effects of heating duration on pathogen viability and immunoglobulin G. J. Dairy Sci. 89:34763483.

Gosiewski, T., D. Jurkiewicz-Badacz, A. Sroka, M. Brzychczy-Włoch, and M. Bulanda. 2014. A novel, nested, multiplex, real-time PCR for detection of bacteria and fungi in blood. BMC Microbiol. $14: 144$

Gourbeyre, P., S. Denery, and M. Bodinie. 2011. Probiotics, prebiotics, and synbiotics: Impact on the gut immune system and allergic reactions. J. Leukoc. Biol. 89:685-695.

Hamer, H. M., D. M. A. E. Jonkers, K. Venema, S. A. L. W. Vanhoutvin, F. J. Troost, and R. J. Brummer. 2008. The role of butyrate on colonic function. Aliment. Pharmacol. Ther. 27:104-119.

Hammon, H. M., I. A. Zanker, and J. W. Blum. 2000. Delayed colostrum feeding affects IGF-I and insulin plasma concentrations in neonatal calves. J. Dairy Sci. 83:85-92.

Hansen, R., R. K. Russell, C. Reiff, P. Louis, F. McIntosh, S. H. Berry, I. Mukhopadhya, W. M. Bisset, A. R. Barclay, J. Bishop, D. M. Flynn, P. McGrogan, S. Loganathan, G. Mahdi, H. J. Flint, E. M. El-Omar, and G. L. Hold. 2012. Microbiota of de-novo pediatric IBD: increased Faecalibacterium prausnitzii and reduced bacterial diversity in Crohn's but not in ulcerative colitis. Am. J. Gastroenterol. 107:1913-1922.

Hernández-Castellano, L. E., A. M. Almeida, M. Ventosa, A. V. Coelho, N. Castro, and A. Argüello. 2014. The effect of colostrum 
intake on blood plasma proteome profile in newborn lambs: Low abundance proteins. BMC Vet. Res. 10:85.

Higuchi, R., C. Fockler, G. Dollinger, and R. Watson. 1993. Kinetic PCR analysis: Real-time monitoring of DNA amplification reactions. Biotechnology (N Y). 11:1026-1030.

Jia, W., R. N. Whitehead, L. Griffiths, C. Dawson, R. H. Waring, D. B. Ramsden, J. O. Hunter, and J. A. Cole. 2010. Is the abundance of Faecalibacterium prausnitzii relevant to Crohn's disease? FEMS Microbiol. Lett. 310:138-144.

Kaevska, M., P. Videnska, K. Sedlar, I. Bartejsova, A. Kralova, and I. Slana. 2016. Faecal bacterial composition in dairy cows shedding Mycobacterium avium subsp. paratuberculosis in faeces in comparison with nonshedding cows. Can. J. Microbiol. 62:538-541.

Kalliomäki, M., M. C. Collado, S. Salminen, and E. Isolauri. 2008. Early differences in fecal microbiota composition in children may predict overweight. Am. J. Clin. Nutr. 87:534-538.

Karstens, L., M. Asquith, V. Caruso, J. T. Rosenbaum, D. A. Fair, J. Braun, W. T. Gregory, R. Nardos, and S. K. McWeeney. 2018. Community profiling of the urinary microbiota: Considerations for low-biomass samples. Nat. Rev. Urol. 15:735-749.

Kostric, M., K. Milger, S. Krauss-Etschmann, M. Engel, G. Vestergaard, M. Schloter, and A. Schöler. 2018. Development of a stable lung microbiome in healthy neonatal mice. Microb. Ecol. 75:529542 .

Kroes, I., P. W. Lepp, and D. A. Relman. 1999. Bacterial diversity within the human subgingival crevice. Proc. Natl. Acad. Sci. USA 96:14547-14552.

Krzyściak, W., K. K. Pluskwa, A. Jurczak, and D. Kościelniak. 2013. The pathogenicity of the Streptococcus genus. Eur. J. Clin. Microbiol. Infect. Dis. 32:1361-1376.

Lane, D. J. 1991. 16S/23S rRNA sequencing. Pages 115-175 in Nucleic Acid Techniques in Bacterial Systematics. E. Stackebrandt, and M. Goodfellow, ed. Wiley, New York, USA.

Li, G., M. Yang, Y. Jin, Y. Li, W. Qian, H. Xiong, J. Song, and X. Hou. 2018. Involvement of shared mucosal-associated microbiota in the duodenum and rectum in diarrhea-predominant irritable bowel syndrome. J. Gastroenterol. Hepatol. 33:1220-1226.

Louis, P., and H. J. Flint. 2017. Formation of propionate and butyrate by the human colonic microbiota. Environ. Microbiol. 19:29-41.

Ludwig, W., K. H. Schleifer, and W. B. Whitman. 2015. Revised road map to the phylum Firmicutes. In Bergey's Manual of Systematic Bacteriology. Vol. 3. 2nd ed. W. B. Whitman ed. Wiley, New York, NY.

Malmuthuge, N., Y. Chen, G. Liang, and L. A. Goonewardene. 2015. Heat-treated colostrum feeding promotes beneficial bacteria colonization in the small intestine of neonatal calves. J. Dairy Sci. 98:8044-8053.

Mez, K., K. A. Beattie, G. A. Codd, K. Hanselmann, B. Hauser, H. Naegeli, and H. R. Preisig. 1997. Identification of a microcystin in benthic cyanobacteria linked to cattle deaths on alpine pastures in Switzerland. Eur. J. Phycol. 32:111-117.

Minich, J. J., Q. Zhu, S. Janssen, R. Hendrickson, A. Amir, R. Vetter, J. Hyde, M. M. Doty, K. Stillwell, J. Benardini, J. H. Kim, E. E. Allen, K. Venkateswaran, and R. Knight. 2018. KatharoSeq enables high-throughput microbiome analysis from low-biomass samples. mSystems 3:e00218-17.

Mohammadi, T., H. W. Reesink, C. M. Vandenbroucke-Grauls, and P. H. Savelkoul. 2005. Removal of contaminating DNA from commercial nucleic acid extraction kit reagents. J. Microbiol. Methods 61:285-288.

Niederhauser, C., C. Höfelein, B. Wegmüller, J. Lüthy, and U. Candrian. 1994. Reliability of PCR decontamination systems. PCR Methods Appl. 4:117-123.

Oikonomou, G., A. G. V. Teixeira, C. Foditsch, M. L. Bicalho, V. S. Machado, and R. C. Bicalho. 2013. Fecal microbial diversity in pre-weaned dairy calves as described by pyrosequencing of metagenomic 16S rDNA. Associations of Faecalibacterium species with health and growth. PLoS One 8:e63157.

Orr, P. T., G. J. Jones, R. A. Hunter, K. Berger, D. A. De Paoli, and C. L. A. Orr. 2001. Ingestion of toxic Microcystis aeruginosa by dairy cattle and the implications for microcystin contamination of milk. Toxicon 39:1847-1854

Osipov, G. A., N. B. Boiko, N. F. Fedosova, S. A. Kasikhina, and K. V. Lyadov. 2009. Comparative gas chromatography-mass spectrometry study of the composition of microbial chemical markers in feces. Microb. Ecol. Health Dis. 21:159-171.

Pajak, B., A. Orzechowski, and B. Gajkowska. 2007. Molecular basis for sodium butyrate-dependent proapoptotic activity in cancer cells. Adv. Med. Sci. 52:83-88.

Patil, P. B., Y. Zeng, T. Coursey, P. Houston, I. Miller, and S. Chen. 2010. Isolation and characterization of a Nocardiopsis sp. from honeybee guts. FEMS Microbiol. Lett. 312:110-118.

Raboisson, D., P. Trillat, and C. Cahuzac. 2016. Failure of passive immune transfer in calves: A meta-analysis on the consequences and assessment of the economic impact. PLoS One 11:e150452.

Ramotar, K., J. M. Conly, H. Chubb, and T. J. Louie. 1984. Production of menaquinones by intestinal anaerobes. J. Infect. Dis. 150:213-218.

Rautava, S., R. Luoto, S. Salminen, and E. Isolauri. 2012. Microbial contact during pregnancy, intestinal colonization and human disease. Nat. Rev. Gastroenterol. Hepatol. 9:565-576.

Rey, M., F. Enjalbert, S. Combes, L. Cauquil, O. Bouchez, and V. Monteils. 2014. Establishment of ruminal bacterial community in dairy calves from birth to weaning is sequential. J. Appl. Microbiol. 116:245-257.

Ruth, M. R., and C. J. Field. 2013. The immune modifying effects of amino acids on gut-associated lymphoid tissue. J. Anim. Sci. Biotechnol. 4:27.

Salter, S. J., M. J. Cox, E. M. Turek, S. T. Calus, W. O. Cookson, M. F. Moffatt, P. Turner, J. Parkhill, N. J. Loman, and A. W. Walker. 2014. Reagent and laboratory contamination can critically impact sequence-based microbiome analyses. BMC Biol. 12:87.

Sassone-Corsi, M., S. P. Nuccio, H. Liu, D. Hernandez, C. T. Vu, A. A. Takahashi, R. A. Edwards, and M. Raffatellu. 2016. Microcins mediate competition among Enterobacteriaceae in the inflamed gut. Nature 540:280-283.

Scheppach, W., and F. Weiler. 2004. The butyrate story: Old wine in new bottles? Curr. Opin. Clin. Nutr. Metab. Care 7:563-567.

Schieber, A. M. P., Y. M. Lee, M. W. Chang, M. Leblanc, B. Collins, M. Downes, R. M. Evans, and J. S. Ayres. 2015. Disease tolerance mediated by microbiome $E$. coli involves inflammasome and IGF-1 signaling. Science 350:558-563.

Schmieder, R., and R. Edwards. 2011. Fast identification and removal of sequence contamination from genomic and metagenomic datasets. PLoS One 6:e17288.

Sheedy, J. R., R. E. H. Wettenhall, D. Scanlon, P. R. Gooley, D. P. Lewis, N. Mcgregor, D. I. Stapleton, H. L. Butt, and K. L. De Meirleir. 2009. Increased d-lactic acid intestinal bacteria in patients with chronic fatigue syndrome. In Vivo 23:621-628.

Smith, P. M., M. R. Howitt, N. Panikov, M. Michaud, C. A. Gallini, M. Bohlooly-Y, J. N. Glickman, and W. S. Garrett. 2013. The microbial metabolites, short-chain fatty acids, regulate colonic Treg cell homeostasis. Science 341:569-573.

Sokol, H., B. Pigneur, L. Watterlot, O. Lakhdari, L. G. BermúdezHumarán, J. J. Gratadoux, S. Blugeon, C. Bridonneau, J. P. Furet, G. Corthier, C. Grangette, N. Vasquez, P. Pochart, G. Trugnan, G. Thomas, H. M. Blottière, J. Doré, P. Marteau, P. Seksik, and P. Langella. 2008. Faecalibacterium prausnitzii is an anti-inflammatory commensal bacterium identified by gut microbiota analysis of Crohn disease patients. Proc. Natl. Acad. Sci. USA 105:1673116736 .

Sommer, F., and F. Bäckhed. 2013. The gut microbiota-Masters of host development and physiology. Nat. Rev. Microbiol. 11:227-238.

Song, Y. 2018. Early life gut microbiome in dairy calves and its responses to colostrum feeding strategies. PhD Thesis. Department of Agricultural, Food and Nutritional Science, University of Alberta, Edmonton, Canada.

Song, Y., N. Malmuthuge, F. Li, and L. L. Guan. 2019. Colostrum feeding shapes the hindgut microbiota of dairy calves during the first $12 \mathrm{~h}$ of life. FEMS Microbiol. Ecol. 95:fiy203. 
Song, Y., N. Malmuthuge, M. A. Steele, and L. L. Guan. 2018. Shift of hindgut microbiota and microbial short chain fatty acids profiles in dairy calves from birth to pre-weaning. FEMS Microbiol. Ecol. 94:fix179.

Stott, G. H., D. B. Marx, B. E. Menefee, and G. T. Nightengale. 1979. Colostral immunoglobulin transfer in calves. III. Amount of absorption. J. Dairy Sci. 62:1902-1907.

Tajima, K., H. Ohmori, M. Tohno, H. Ohtsu, T. Tsukahara, and R. Aminov. 2013. Segmented filamentous bacteria are a major group in terminal ileum of piglets. Anaerobe 23:109-111.

Tourneur, E., and C. Chassin. 2013. Neonatal immune adaptation of the gut and its role during infections. Clin. Dev. Immunol. 2013:270301.

Van den Abbeele, P., T. Van de Wiele, W. Verstraete, and S. Possemiers. 2011. The host selects mucosal and luminal associations of coevolved gut microorganisms: A novel concept. FEMS Microbiol. Rev. 35:681-704.

Wall, R., S. G. Hussey, C. A. Ryan, M. O'neill, G. Fitzgerald, C. Stanton, and R. P. Ross. 2008. Presence of two Lactobacillus and Bifidobacterium probiotic strains in the neonatal ileum. ISME J. 2:83.

Wrzosek, L., S. Miquel, M. L. Noordine, S. Bouet, M. J. ChevalierCurt, V. Robert, C. Philippe, C. Bridonneau, C. Cherbuy, C. Robbe-Masselot, and P. Langella. 2013. Bacteroides thetaiotaomicron and Faecalibacterium prausnitzii influence the production of mucus glycans and the development of goblet cells in the colonic epithelium of a gnotobiotic model rodent. BMC Biol. 11:61.

$\mathrm{Yu}, \mathrm{Z}$., and M. Morrison. 2004. Improved extraction of PCR-quality community DNA from digesta and fecal samples. Biotechniques $36: 808-812$. 